\title{
Impact of Climate Change on the Development of Rainfall Intensity, Duration and Frequency Curves in Chiro and Hurso Stations of Eastern Ethiopia
}

\author{
Abeba Tesfay, Shoeb Quraishi \\ Department of Natural Resource and Environmental Engineering, Haramaya University, Haramaya, Ethiopia
}

Email address:

sweetabeba43@gmail.com (A. Tesfay)

To cite this article:

Abeba Tesfay, Shoeb Quraishi. Impact of Climate Change on the Development of Rainfall Intensity, Duration and Frequency Curves in Chiro and Hurso Stations of Eastern Ethiopia. Earth Sciences. Vol. 6, No. 5, 2017, pp. 97-105. doi: 10.11648/j.earth.20170605.16

Received: June 5, 2017; Accepted: June 26, 2017; Published: September 18, 2017

\begin{abstract}
Today environmental issue becomes the biggest concern of humankind because of scientific evidence about the increasing concentration of greenhouse gases in the atmosphere and the changing climate of the Earth. This study was conducted in eastern Ethiopia specifically at Chiro and Hurso stations. The study assessed quantitatively the rainfall Intensity Duration Frequency (IDF) relationships under changing climate condition and compare with the existing rainfall- Intensity Duration- Frequency (IDF) relationships. Rainfall intensity duration and frequency curves were developed using historical rainfall time series data under the assumption that climate is stationary. This assumption is not valid under changing climatic conditions that may shifts in the magnitude and frequency of extreme rainfall. Such shifts in extreme rainfall at the local level demand new regulations for any intervention management as well as changes in design practices. In order to estimate the level of climate change impact on the rainfall Intensity Duration Frequency (IDF) relationships, these changes of the climate variables were applied to Hyetos Temporal Rainfall Disaggregation model to simulate future IDF relationships. From the results can see graphical presentation of IDF curves for return periods of 2, 5, 10, 25, 50 and 100 years for durations of 1, 2, 3, 6,12 and 24 hours. The comparison results indicate that, difference between rainfall intensities (percentage) of climate change scenario and historic rainfall for $2020 \mathrm{~s}$ ranges between $1.58 \%$ and $10.92 \%$ for $2050 \mathrm{~s}$, ranges between $0.07 \%$ and $20.22 \%$ and for 2080 s, ranges between $0.71 \%$ and $55.93 \%$ in Chiro station, respectively. Similarly, in the case of Hurso station, the difference between climate change scenario and historic rainfall for 2020 s ranges between $1.10 \%$ and $27.83 \%$ for 2050 s ranges between $110.5 \%$ and $40.21 \%$ and for 2080 s that ranges between $19.44 \%$ and $67.75 \%$, respectively. Therefore, the outputs of the study indicates that the rainfall magnitude will be different in the future and thereby the decrease and increase in rainfall intensity and magnitude may have major implications on ways in which current and future intervention is designed, operated, and maintained. Therefore, design standards and guidelines currently employed in the study area should be revised with the confirmation of the impacts of climate change.
\end{abstract}

Keywords: Climate Change, Rainfall Intensity, Duration and Frequency Curves, Ethiopia

\section{Introduction}

Nowadays, environmental issue becomes the biggest concern of humankind because of scientific evidence about the increasing concentration of greenhouse gases in the atmosphere and the changing climate of the Earth. Globally, temperature is increasing and the amount and distribution of rainfall is being altered [1]. According to the International Panel on Climate Change [2] Scientific Assessment Report, global average temperature would rise between 1.4 and $5.8^{\circ} \mathrm{C}$ by 2100 with the doubling of the $\mathrm{CO}_{2}$ concentration in the atmosphere. Sea level rise, change in precipitation pattern (up to $\pm 20 \%$ ), and change in other local climate conditions are expected to occur because of intensifying global temperature [1]. Extreme high precipitation amounts are among environmental events with the most disastrous consequences for society. Estimates of their return periods and design values are of great importance in hydrologic modeling, engineering practice for water resource systems and reservoirs design and management, planning for weather- 
related emergencies, etc [3].

According to [4] the Intensity-Duration-Frequency curves (IDF curves) are plots of rainfall intensity versus duration of rainfall events. Usually, there are several curves on a single graph, one for each of several different rainfall frequencies (return periods). These curves are hyperbolic or exponential decay type curves, which vary by geographical locations. Rainfall intensity measurements are used by engineers, landuse planners, and water-resource managers to design safe and economical structures for the control, storage, and routing of storm and surface water. The curves also are used as input to rainfall-runoff models that are used to simulate large floods for bridge and spillway design. Soil erosion prevention practices and irrigation management procedures also are based on reliable predictions of rainfall intensities [5]. In fact, the variability of rainfall in time and in space causes its occurrence very difficult to predict. The distribution and occurrence of rainfall is not uniform; rather it has spatial as well as temporal variation. Thus accepting a certain amount of risk that the capacity may be exceeded [6].

In Ethiopia situation, the climate is characterized by high rainfall variability. Therefore, the knowledge of year to year rainfall variation is useful for planning and management of water resource systems. Most central and eastern highlands of the country are characterized by less than $30 \% \mathrm{CV}$ values and this value increases to $70 \%$ or more to the lowland of the north, northeast and southeast [7]. Generally, the value of CV varies from $10 \%$ to $70 \%$ in the country. The low rainfall areas of the north, northeastern and southeastern regions are characterized by high $\mathrm{CV}$ values and are vulnerable to drought.

As early in 1932 elsewhere the establishment of IDF relationships was done. Since then, many sets of IDF relationships have been constructed for several parts of the globe [8]. in many developing countries, as well as Ethiopia because of the adequate long historical datasets are not available. According to [8], the General, hydrological information like IDF being the principal input of design of water resources, drainage works, soil conservation programs and other similar sectors, it is not yet well developed and not readily available in a systematic relationship to the concerned users. The IDF relationship is an important hydrologic tool which will bridge the gap between the design need and the unavailability of design information especially in planning and design of water resources projects.

Due to lack of these IDF relationships, the planning and design of water resource development, irrigation and drainage schemes, soil conservation programs and other projects are based on some assumptions and empirical data from other countries [8]. And owing the unavailability of IDF under climate change relationships in the study areas, the planning and design of water resource development, irrigation and drainage schemes, soil conservation programs and other similar projects are based on some assumptions and empirical data from other countries. Therefore, in order to harness the available water resources, it is important to have adequate knowledge on the rainfall magnitude, its duration, and frequency under climate change, which requires for planning and design of drainage works, water resource systems and flood control, culvert design and for soil conservation interventions and Investigating how the climate change impacts on IDF is necessary for the specific area. In addition, IDF reduce planning error and save time to plan increase accuracy. Apart from its usefulness in agricultural planning, the result of this work can also be used in water resources management and construction activities. Therefore, the objective of the study was: to develop rainfall IDF relationships for Chiro and Hurso stations under changing climate conditions and compare with the existing rainfall intensity duration frequency relationship.

\section{Materials and Methods}

The study was carried out in eastern Ethiopia specifically at Chiro and Hurso meteorological stations. Chiro is Located in West Hararghe Zone in eastern Ethiopia. It has $9^{\circ} 07 \mathrm{~N}$ latitude, $40^{\circ} 86 \mathrm{E}$ longitude and an altitude of 1815 meters above sea level and Hursois Located in the Shinile Zone of the Somali Region, in eastern Ethiopia, it has $9^{\circ} 96 \mathrm{~N}$ latitude, $41^{\circ} 67 \mathrm{E}$ longitude and an altitude of 1110 meters above sea level. The criteria used for selection of stations were: geographically representative, type of station needs to be first class and length of record has to be more than ten years. The rainfall pattern is bimodal and the mean annual rainfall is $541.3 \mathrm{~mm}$ and $797.14 \mathrm{~mm}$ for Hurso and Chiro respectively and with a relatively lesser amount during the small rainy season or belg (March to April). The main rainy season (kremt) lies during the months of July to September and another rain (belg) during the months of March to May.

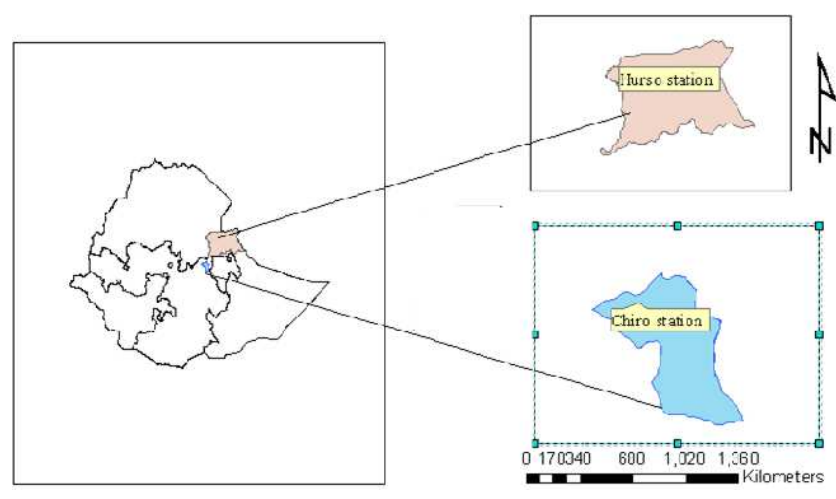

Figure 1. Location map of the study area.

\subsection{Methods}

The data source were the automatically recorded rainfall charts collected in National Meteorological Service Agency (NMSA) and the climatic data used for SDSM were collected from the Canadian Institute for climate studies Website for model output of HadCM3. Global circulation data for the selectedmodelsfromwww.pcmdi.llnl.gov/ipcc/about_ipcc.php website. In order to investigate climate change impact on the IDF curve, rainfall data are downscaled from two GCMs (HadCM3 and CGCM3) with the A2 emissions scenario and 
rainfall frequency analysis was carried out. After downscaling and frequency analysis estimation, disaggregation of daily rainfall in to hourly values using the method Hyetos Temporal Rainfall Disaggregation model and finally an IDF curve was developed. The historic daily rainfalls at the two stations were modified by multiplying rainfall data with the monthly percentage change values This means that if the change field for the month of January is $+10 \%$, then all January values in the historic record are multiplied by 1.10 ; similarly, if the change field is $-15 \%$ for the same month, all historic data is multiplied by 0.85 [9], [10].

To Development of IDF Curves Using Frequency Analysis Annual maximum rainfall data at stations were analyzed using the method of frequency analysis and applying mathematical relationships. Data analysis and fitting the theoretical probability distribution to the observed data as well as numerical computation of the extreme rainfall magnitude $\left(x_{T}\right)$ were made for the required durations and frequencies based on the selected probability distribution function. The extracted annual maximum rainfall data arranged in descending order were fitted to the probability distribution functions. The rainfall depths at the durations of 1, 2, 3, 5, 6, 12 and 24 hours were fitted to Gumbel Extreme value TypeI (EVI) using frequency analysis technique. the Gumbel Extreme Value type I distribution (EVI) is the most widely used probability distribution model for extreme values in hydrologic and meteorological studies and has received the highest application for estimating large events in various part of the world. This distribution has been used for rainfall depth-duration-frequency studies [11].Similarly the reason for selecting this distribution for analysis is due to the fact that commonly used in rainfall and flood studies [9], [12] [13], [14], [15].

Table 1. R-square values for Hurso and Chiro stations.

\begin{tabular}{|c|c|c|c|c|c|c|c|}
\hline \multirow{2}{*}{ Station name } & \multirow{2}{*}{ Type of Distribution } & \multicolumn{6}{|c|}{ R-square Value for the Indicated Duration (hr) } \\
\hline & & 1 & 2 & 3 & 6 & 12 & 24 \\
\hline \multirow{3}{*}{ Hurso } & Gumbel Extreme Value type I (EVI) & 0.921 & 0.978 & 0.975 & 0.972 & 0.974 & 0.962 \\
\hline & Lognormal & 0.923 & 0.96 & 0.954 & 0.954 & 0.976 & 0.964 \\
\hline & Log Pearson & 0.966 & 0.976 & 0.964 & 0.926 & 0.968 & 0.969 \\
\hline \multirow{3}{*}{ Chiro } & Gumbel Extreme Value type I (EVI) & 0.979 & 0.98 & 0.976 & 0.97 & 0.991 & 0.955 \\
\hline & Lognormal & 0.933 & 0.929 & 0.947 & 0.96 & 0.97 & 0.92 \\
\hline & Log Pearson & 0.962 & 0.946 & 0.968 & 0.967 & 0.99 & 0.96 \\
\hline
\end{tabular}

\section{Results and Discussion}

\subsection{Extreme Rainfall Values (XT)}

The selected Gumbel EVI probability distribution was used to calculate the extreme rainfall values (XT) at different rainfall durations and return periods to form the historical IDF curves for the stations. According to [16], the extreme rainfall values $\left(\mathrm{X}_{\mathrm{T}}\right)$ for the required return periods $(2,5,10,25,50$ and 100) were computed using the proposed probability distribution (Gumble EVI) to form the IDF curves under changing climate for the study area.

$$
y_{T}=\bar{y}+K_{T} S_{y} \rightarrow \mathrm{XT}={ }^{\left(\bar{y}+K_{T} S_{y}\right)} \text {, Where } \mathrm{yT} \text { is the }
$$

reduced variate, $\bar{y}$ and $\mathrm{Sy}$ are the mean and standard deviation of the log transformed data, respectively, and $\mathrm{KT}$ is frequency factor. The computed extreme rainfall values for the durations of interest; 1, 2, 3, 6, 12 and 24 hours and return periods of 2, 5, 10, 25, 50 and 100 years computed for Chiro station is presented in Table 2(a, b and c).Calculated extreme rainfall events (XT) was directly related to both return period and duration of rainfall event; i.e. for each return period the values of extreme rainfall events increases with increasing the rainfall durations and for each duration it increase with increasing of return period as shown in the table 2 below. Historic, A2a and B2a climate scenario data of (2020s, 2050s and 2080s) time horizons for the stations.
Table 2. Calculated extreme rainfall events $\left(X_{T}\right)$ at Chiro station existing and climate change scenarios (2020s, 2050s and 2080s) time horizons respectively.

\begin{tabular}{lllllll}
\hline Return & \multicolumn{6}{c}{ Rainfall $\boldsymbol{x} \boldsymbol{T}(\mathbf{m m})$ for the Indicated Duration $\boldsymbol{D i}(\mathrm{hrs})$} \\
\cline { 2 - 7 } $\operatorname{period}(\mathbf{T})$ & $\mathbf{1}$ & $\mathbf{2}$ & $\mathbf{3}$ & $\mathbf{6}$ & $\mathbf{1 2}$ & $\mathbf{2 4}$ \\
\hline 2 & 21.98 & 25.20 & 28.80 & 32.83 & 34.85 & 37.57 \\
5 & 27.79 & 31.40 & 34.41 & 39.15 & 40.91 & 43.72 \\
10 & 31.63 & 35.51 & 38.12 & 43.33 & 44.93 & 47.79 \\
25 & 36.49 & 40.70 & 42.80 & 48.62 & 50.00 & 52.93 \\
50 & 40.09 & 44.55 & 46.28 & 52.54 & 53.76 & 56.75 \\
100 & 43.67 & 48.37 & 49.73 & 56.44 & 57.50 & 60.53 \\
\hline
\end{tabular}

A, existing (historic).

\begin{tabular}{lllllll}
\hline \multirow{2}{*}{$\begin{array}{l}\text { Return } \\
\text { period (T) }\end{array}$} & \multicolumn{6}{c}{ Rainfall $\boldsymbol{x} \boldsymbol{T}(\mathbf{m m})$ for the Indicated Duration $\boldsymbol{D i ( h r s )}$} \\
\cline { 2 - 7 } & $\mathbf{1}$ & $\mathbf{2}$ & $\mathbf{3}$ & $\mathbf{6}$ & $\mathbf{1 2}$ & $\mathbf{2 4}$ \\
\hline 2 & 24.12 & 32.73 & 35.40 & 40.16 & 45.98 & 47.68 \\
5 & 34.86 & 46.31 & 49.89 & 60.32 & 66.68 & 70.04 \\
10 & 41.97 & 55.30 & 59.48 & 73.66 & 80.38 & 84.85 \\
25 & 50.96 & 66.66 & 71.59 & 90.52 & 97.69 & 103.55 \\
50 & 57.63 & 75.08 & 80.58 & 103.02 & 110.53 & 117.43 \\
100 & 64.25 & 83.45 & 89.51 & 115.44 & 123.28 & 131.20 \\
\hline
\end{tabular}

B, 2020s scenario

\begin{tabular}{lllllll}
\hline \multirow{2}{*}{$\begin{array}{l}\text { Return } \\
\text { period (T) }\end{array}$} & \multicolumn{6}{c}{ Rainfall $\boldsymbol{x} \boldsymbol{T}(\mathbf{m m})$ for the Indicated Duration $\boldsymbol{D i}(\mathrm{hrs})$} \\
\cline { 2 - 7 } & $\mathbf{1}$ & $\mathbf{2}$ & $\mathbf{3}$ & $\mathbf{6}$ & $\mathbf{1 2}$ & $\mathbf{2 4}$ \\
\hline 2 & 19.39 & 23.68 & 29.71 & 38.20 & 46.86 & 51.35 \\
5 & 25.35 & 31.16 & 37.51 & 46.13 & 59.19 & 64.27 \\
10 & 29.29 & 36.12 & 42.68 & 51.37 & 67.36 & 72.82 \\
25 & 34.27 & 42.37 & 49.21 & 58.00 & 77.68 & 83.63 \\
50 & 37.97 & 47.02 & 54.05 & 62.92 & 85.34 & 91.64 \\
100 & 41.64 & 51.63 & 58.86 & 67.80 & 92.94 & 99.60 \\
\hline
\end{tabular}

C, 2050s scenario. 


\begin{tabular}{lllllll}
\hline $\begin{array}{l}\text { Return } \\
\text { period }(\mathbf{T})\end{array}$ & \multicolumn{6}{c}{ Rainfall $\boldsymbol{x} \boldsymbol{T}(\mathbf{m m})$ for the Indicated Duration $\boldsymbol{D i}(\mathbf{h r s})$} \\
\cline { 2 - 7 } & $\mathbf{1}$ & $\mathbf{2}$ & $\mathbf{3}$ & $\mathbf{6}$ & $\mathbf{1 2}$ & $\mathbf{2 4}$ \\
\hline 2 & 22.16 & 27.98 & 31.19 & 36.90 & 39.65 & 44.44 \\
5 & 32.87 & 41.40 & 45.28 & 51.26 & 55.66 & 62.30 \\
10 & 39.96 & 50.28 & 54.62 & 60.76 & 66.26 & 74.13 \\
25 & 48.93 & 61.50 & 66.41 & 72.77 & 79.65 & 89.07 \\
50 & 55.57 & 69.83 & 75.16 & 81.67 & 89.58 & 100.15 \\
100 & 62.17 & 78.09 & 83.84 & 90.52 & 99.44 & 111.16 \\
\hline
\end{tabular}

D, 2080s scenario.

The Table 2 above, the calculated rainfall quintiles at Chiro station shows light increase for the shorter duration (1-hr) under climate scenario in 2020s time lines. Whilst, there will be a slight decrease under 2050s time horizon with relative to 2080s time horizon. On the other hand, for the longer duration (24-hr), there would be a slight increase in 2020s with slight decrease by 2050s and 2080s time horizon.

Estimated rainfall intensity (I), The calculation of rainfall intensity was made by dividing the computed extreme rainfall value based on return period by the individual durations. Hence, intensity (I)can be calculated using the following expression

$$
I=\frac{\text { Rainfall depth }(\mathrm{mm})}{\text { Duration }(\mathrm{hr})}=\frac{x_{T}}{D_{i}} \text { Where XT rainfall depth }
$$

(mm) Di duration (hr)

Table 3. Rainfall intensity $(\mathrm{mm} / \mathrm{hr})$ at Chiro station for Existing, 2020s, 2050s and 2080s respectively.

\begin{tabular}{lllllll}
\hline \multirow{2}{*}{$\begin{array}{l}\text { Return } \\
\text { period (T) }\end{array}$} & \multicolumn{6}{l}{$\begin{array}{l}\text { Intensity of Rainfall (mm/hr) for the Indicated } \\
\text { Duration } \boldsymbol{D}(\mathbf{h r s})\end{array}$} \\
\cline { 2 - 7 } & $\mathbf{1}$ & $\mathbf{2}$ & $\mathbf{3}$ & $\mathbf{6}$ & $\mathbf{1 2}$ & $\mathbf{2 4}$ \\
\hline 2 & 21.98 & 12.6 & 9.60 & 5.47 & 2.90 & 1.57 \\
5 & 27.79 & 15.7 & 11.47 & 6.52 & 3.41 & 1.82 \\
10 & 31.63 & 17.75 & 12.71 & 7.22 & 3.74 & 1.99 \\
25 & 36.49 & 20.35 & 14.27 & 8.10 & 4.17 & 2.21 \\
50 & 40.09 & 22.28 & 15.43 & 8.76 & 4.48 & 2.36 \\
100 & 43.67 & 24.19 & 16.58 & 9.41 & 4.79 & 2.52 \\
\hline
\end{tabular}

A, Historic/existing.

\begin{tabular}{lllllll}
\hline \multirow{2}{*}{$\begin{array}{l}\text { Return } \\
\text { period (T) }\end{array}$} & \multicolumn{6}{l}{$\begin{array}{l}\text { Intensity of Rainfall (mm/hr) for the Indicated } \\
\text { Duration } \boldsymbol{D}(\mathbf{h r s})\end{array}$} \\
\cline { 2 - 7 } & $\mathbf{1}$ & $\mathbf{2}$ & $\mathbf{3}$ & $\mathbf{6}$ & $\mathbf{1 2}$ & $\mathbf{2 4}$ \\
\hline 2 & 24.12 & 16.36 & 11.80 & 6.69 & 3.83 & 1.99 \\
5 & 34.86 & 23.15 & 16.63 & 10.05 & 5.56 & 2.92 \\
10 & 41.97 & 27.65 & 19.83 & 12.28 & 6.70 & 3.54 \\
25 & 50.96 & 33.33 & 23.86 & 15.09 & 8.14 & 4.31 \\
50 & 57.63 & 37.54 & 26.86 & 17.17 & 9.21 & 4.89 \\
100 & 64.25 & 41.72 & 29.84 & 19.24 & 10.27 & 5.47 \\
\hline
\end{tabular}

B, 2020s scenario.

\begin{tabular}{lllllll}
\hline \multirow{2}{*}{$\begin{array}{l}\text { Return } \\
\text { period (T) }\end{array}$} & \multicolumn{6}{l}{$\begin{array}{l}\text { Intensity of Rainfall (mm/hr) for the Indicated } \\
\text { Duration } \boldsymbol{D}(\mathbf{h r s})\end{array}$} \\
\cline { 2 - 7 } & $\mathbf{1}$ & $\mathbf{2}$ & $\mathbf{3}$ & $\mathbf{6}$ & $\mathbf{1 2}$ & $\mathbf{2 4}$ \\
\hline 2 & 19.39 & 11.84 & 9.90 & 6.37 & 3.90 & 2.14 \\
5 & 25.35 & 15.58 & 12.50 & 7.69 & 4.93 & 2.68 \\
10 & 29.29 & 18.06 & 14.23 & 8.56 & 5.61 & 3.03 \\
25 & 34.27 & 21.19 & 16.40 & 9.67 & 6.47 & 3.48 \\
50 & 37.97 & 23.51 & 18.02 & 10.49 & 7.11 & 3.82 \\
100 & 41.64 & 25.81 & 19.62 & 11.30 & 7.74 & 4.15 \\
\hline
\end{tabular}

C, 2050s scenario.

\begin{tabular}{lllllll}
\hline \multirow{2}{*}{$\begin{array}{l}\text { Return } \\
\text { period (T) }\end{array}$} & \multicolumn{6}{l}{$\begin{array}{l}\text { Intensity of Rainfall (mm/hr) for the Indicated } \\
\text { Duration } \boldsymbol{D}(\mathbf{h r s})\end{array}$} \\
\cline { 2 - 7 } & $\mathbf{1}$ & $\mathbf{2}$ & $\mathbf{3}$ & $\mathbf{6}$ & $\mathbf{1 2}$ & $\mathbf{2 4}$ \\
\hline 2 & 22.16 & 13.99 & 10.40 & 6.15 & 3.30 & 1.85 \\
5 & 32.87 & 20.70 & 15.09 & 8.54 & 4.64 & 2.60 \\
10 & 39.96 & 25.14 & 18.21 & 10.13 & 5.52 & 3.09 \\
25 & 48.93 & 30.75 & 22.14 & 12.13 & 6.64 & 3.71 \\
50 & 55.57 & 34.91 & 25.05 & 13.61 & 7.47 & 4.17 \\
100 & 62.17 & 39.05 & 27.95 & 15.09 & 8.29 & 4.63 \\
\hline
\end{tabular}

D, 2080sscenario.

As shown in Table 3 above highest intensity of rainfall $(24.12 \mathrm{~mm} / \mathrm{hr})$ for 2years recurrence interval within $1-\mathrm{hr}$ duration was observed in 2020s while the lowest $(19.39 \mathrm{~mm} / \mathrm{hr})$ was observed in $2050 \mathrm{~s}$. Besides, the daily maximum intensity of rainfall was found to be highest $(2.14 \mathrm{~mm} / \mathrm{hr})$ at $2050 \mathrm{~s}$ while the lowest one $(1.57 \mathrm{~mm} / \mathrm{hr})$ was for existing. On the other hand, the highest rainfall intensity $(64.25 \mathrm{~mm} / \mathrm{hr})$ at1-hrduration is likely to occur in $2020 \mathrm{~s}$ and relatively the lowest $(41.64 \mathrm{~mm} / \mathrm{hr})$ intensity of rainfall occur in2050sfor 100 years of recurrence interval.

Generality for the given return periods, the values of the calculated intensities decreases as the rainfall duration increase. But, the rainfall intensity increases with an increase in return period for each duration. These calculated rainfall intensities were used as input data for estimating the IDF parameters. Therefore, using the computed rainfall intensity values of different durations and return periods, the IDF curves for selected stations were constructed.

\subsection{IDF Curves for the Stations Under Climate Change}

The IDF relationships were established for Southern Nations and Nationalities and Peoples Regional State, by [17] from the department of Hydrology and Water Resources management, Arba Minich University on his MSc thesis. Recently, [18] produced IDF curves and parameters for Eastern Oromia and [19] developed regional IDF curves for the Oromia Region for some given durations and frequencies, which are now still in use for the stations. Still New infrastructure is typically designed based on historical information on weather and climate extremes. This assumption is not valid under changing climatic conditions that may bring shifts in the magnitude and frequency of extreme rainfall. Such shifts in extreme rainfall at the local level demand new regulations for water infrastructure management as well as changes in design practices [20].

Therefore, with changing climate, it is necessary to thoroughly review and/or update the current design standards, of any intervention, therefore using the values of climate change in Table 2 in the above Intensity of Rainfall IDF curves were plotted for 2020s, 2050s and 2080s for Chiro and hurso stations as shown below in the figures represents the IDF curves of the selected scenarios for all durations. The IDF curves were plotted by origin software, using the duration $\left(\mathrm{T}_{\mathrm{d}}\right)$, as abscissa (x-axis) and the intensity (I), as ordinate (y-axis) as shown in Figures 2, below for Chiro and Hurso respectively. 


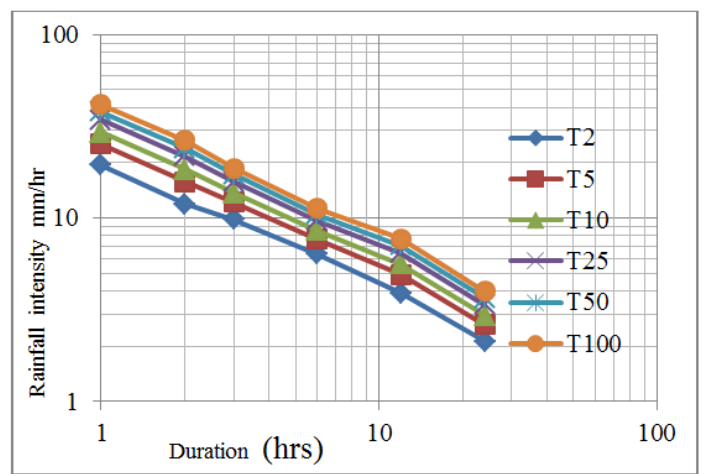

a) IDF for Historic /existing Chiro

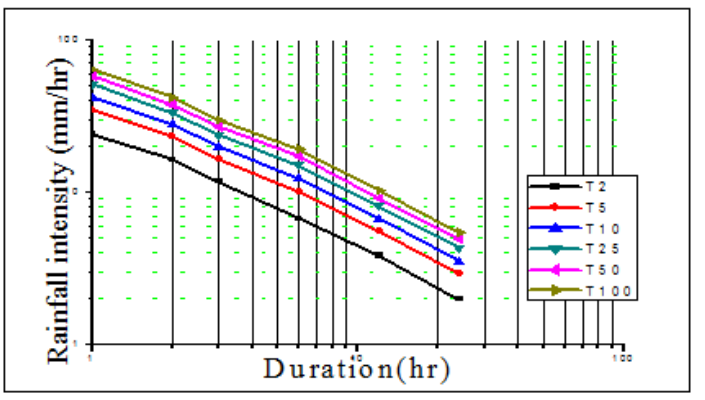

b) IDF for 2020s Chiro

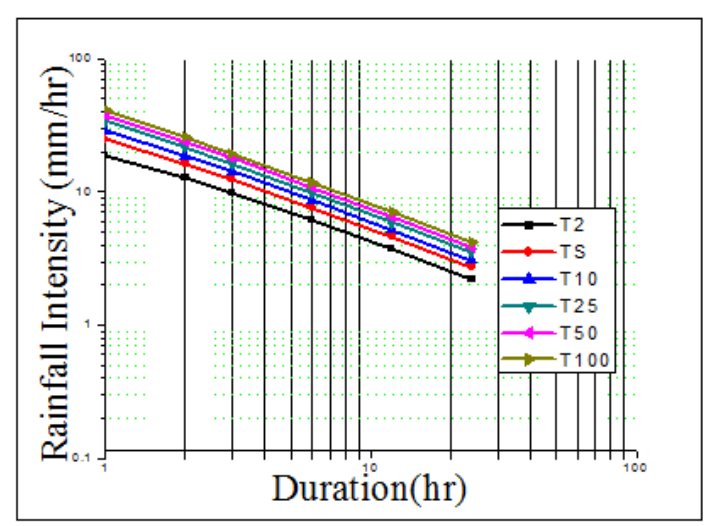

c) IDF for 2050s Chiro

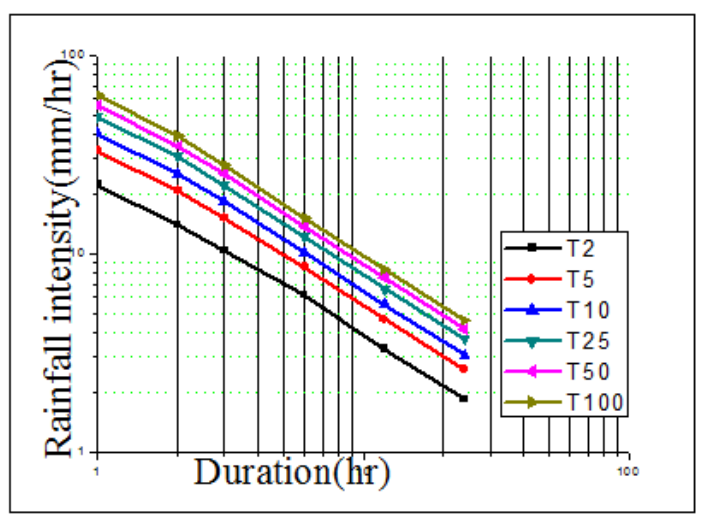

d) IDF for2080s Chiro

Figure 2. IDF curves for Chiro station under climate change.

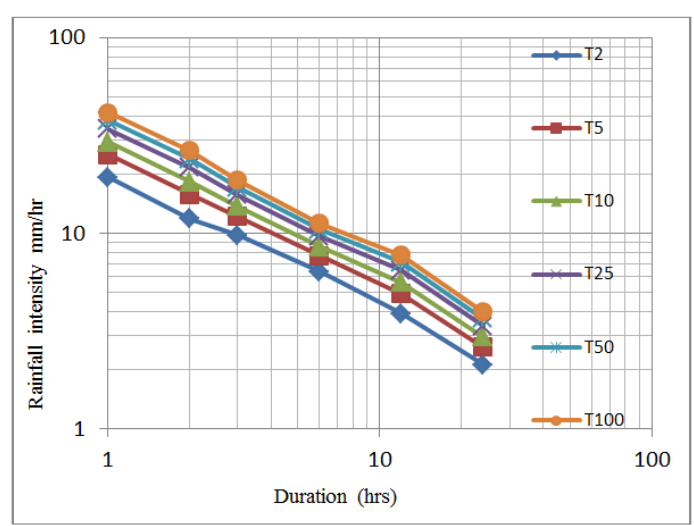

a) IDF for Historic/existing hurso

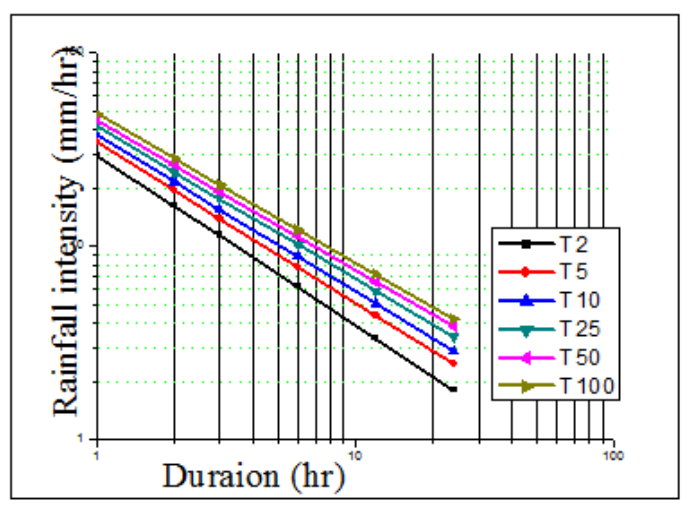

b) IDF for 2020s scenario hurso

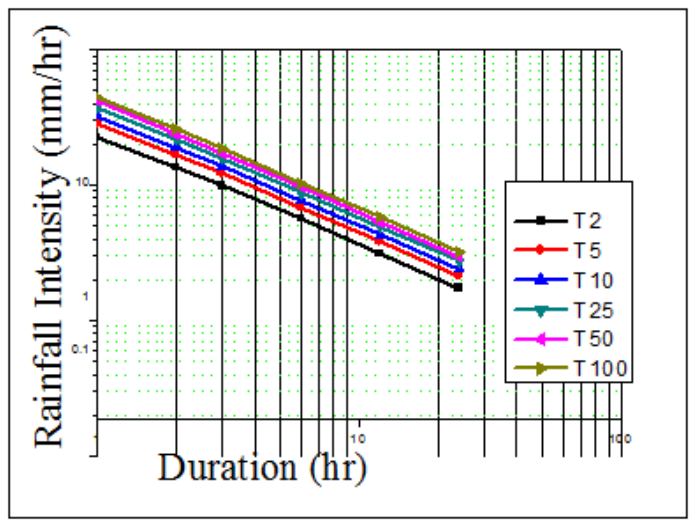

c) IDF for 2050 s scenario hurso

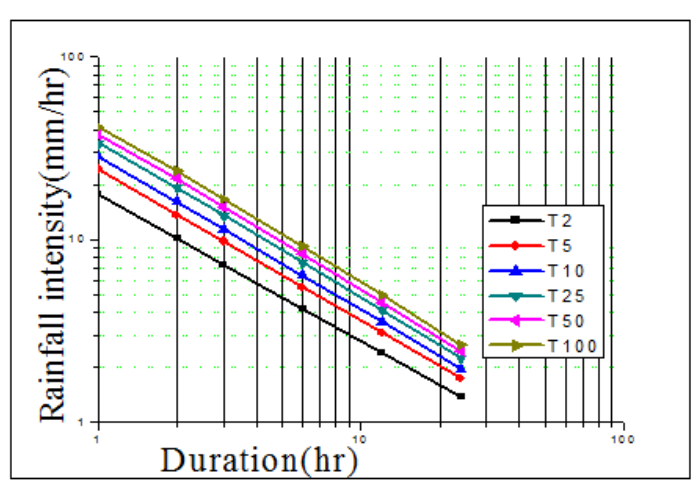

d) IDF For 2080s scenario hurso

Figure 3. IDF curves for Hurso station under climate change. 
The plots should provide the information or serve to meet the need for rainfall IDF relationships in the study area for return periods of 2 to 100 years under climate change condition.

\subsection{Comparison of IDF Results}

Comparison of IDF results was made between IDF curve developed under climate change scenarios with the historic rainfall (IDF) relationships for Chiro and Hurso stations as well. Relative difference between the curves is determined using the following relationship [20], [21], [9] as

$$
\text { Difference }=\frac{\left|x_{1}-x_{2}\right|}{\frac{\left(x_{1}+x_{2}\right)}{2}} \times 100
$$

Chiro Station, the model estimations show different results, with the extreme rainfall. In 2020s, climate change shows slight decrease and increase in rainfall intensity than the existing rainfall intensity while the two scenarios (2050s and 2080s) shows decrease under climate change for all durations(1, 2, 3, 6, 12 and 24 hours) and return periods.

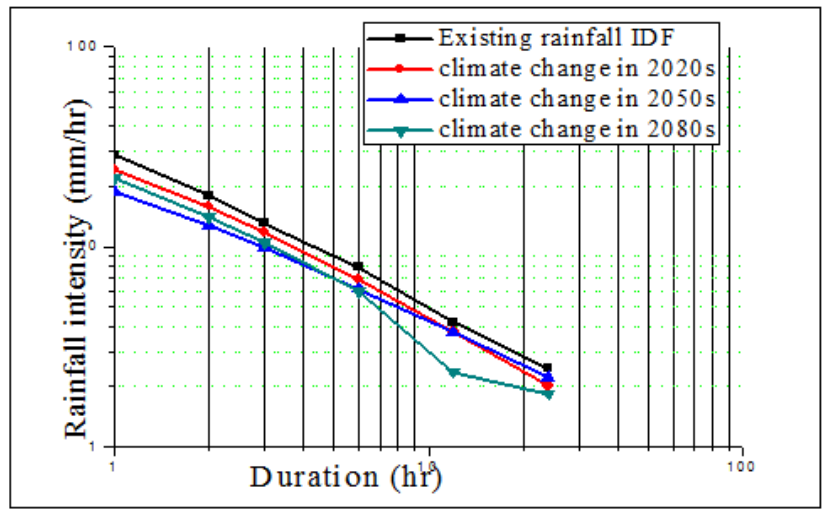

a) For 2 year return period

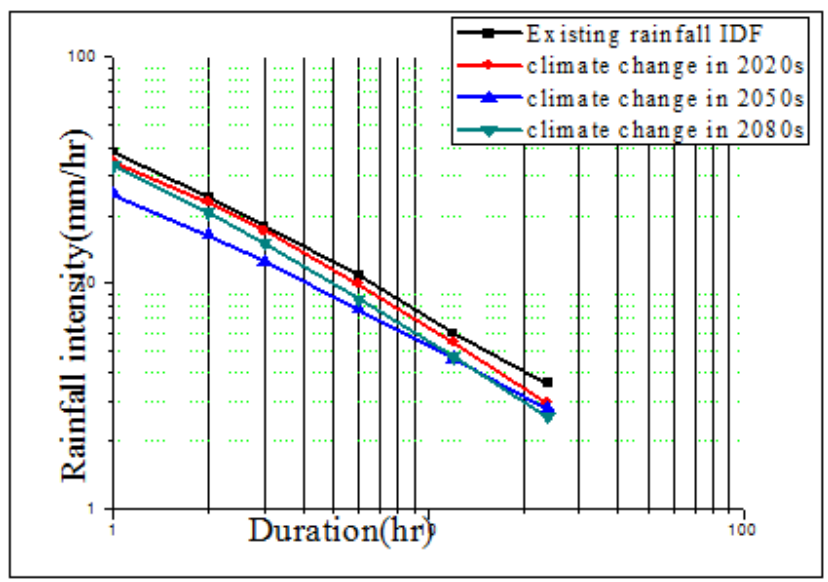

b) For 5 year return period

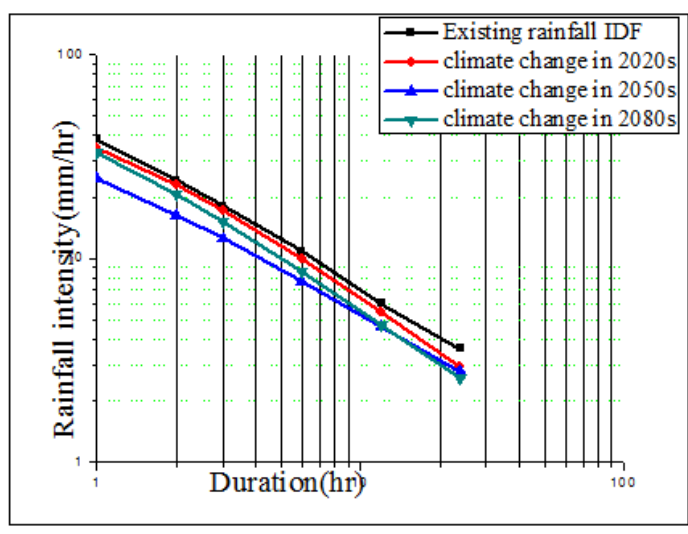

c) For 10 year return period

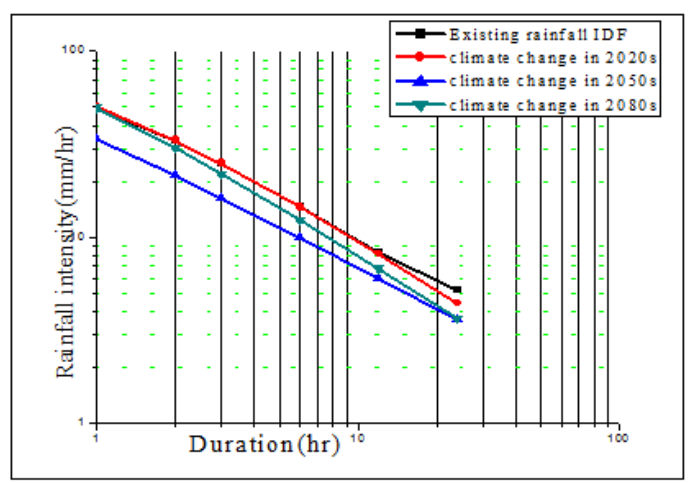

d) For 25 year return period

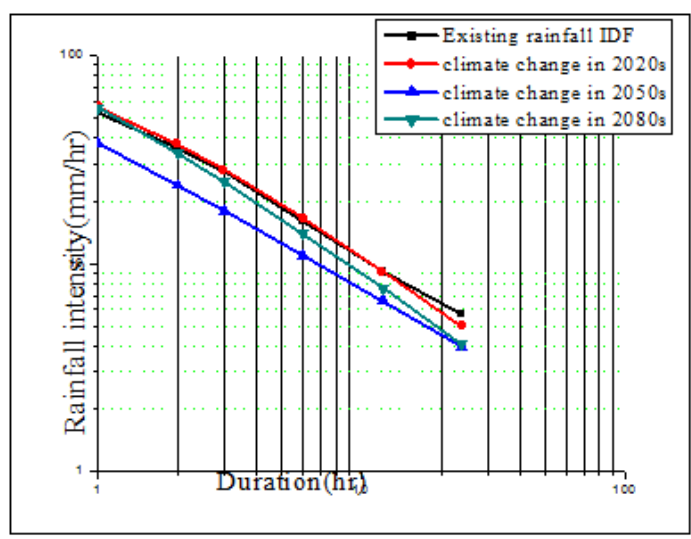

e) For50 year return period

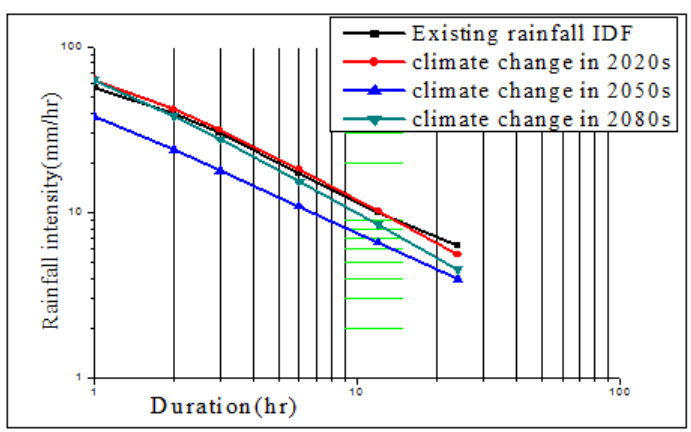

f) For 100 year return period

Figure 4. Comparison of rainfall IDF curves for the given return periods for Chiro station. 
Hurso station, Results of the comparison between historic rainfall and climate change rainfall intensity data set for specified return periods indicate that, the rainfall magnitude might decrease for all duration (1, 2, 3, 6, 12 and 24 hours) for all return periods. And also the rainfall magnitude might decrease for return periods of 2, 5, 10, 25, 50 and 100 due to climate change as indicated in Figures below.

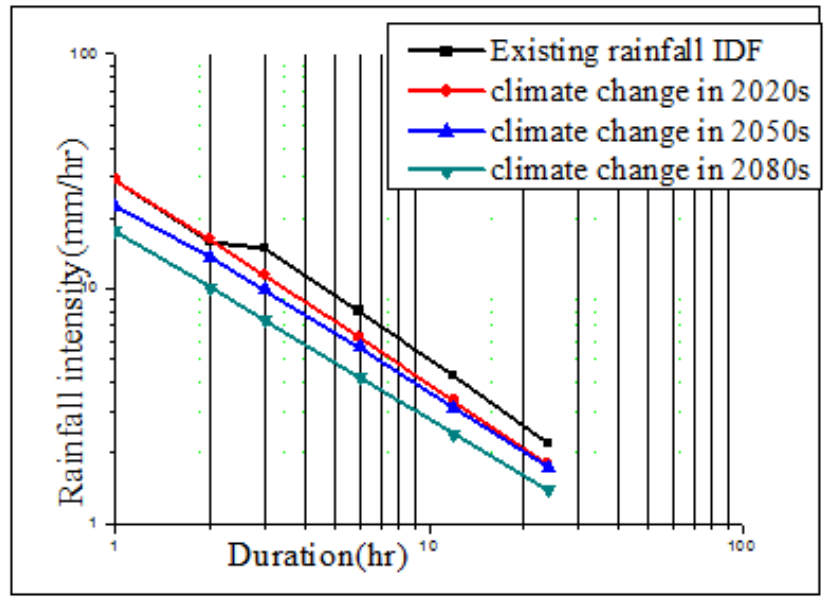

a) For 2 year return period

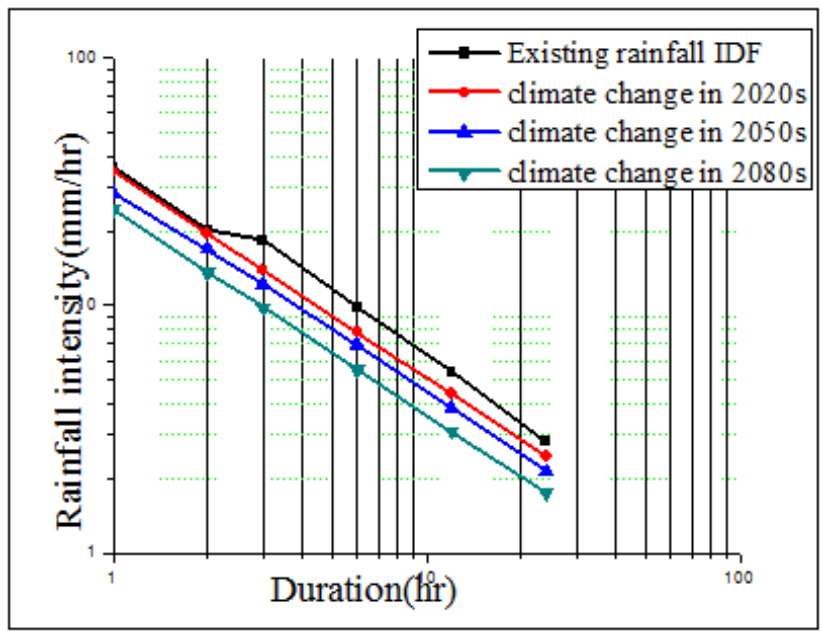

b) For 5 year return period

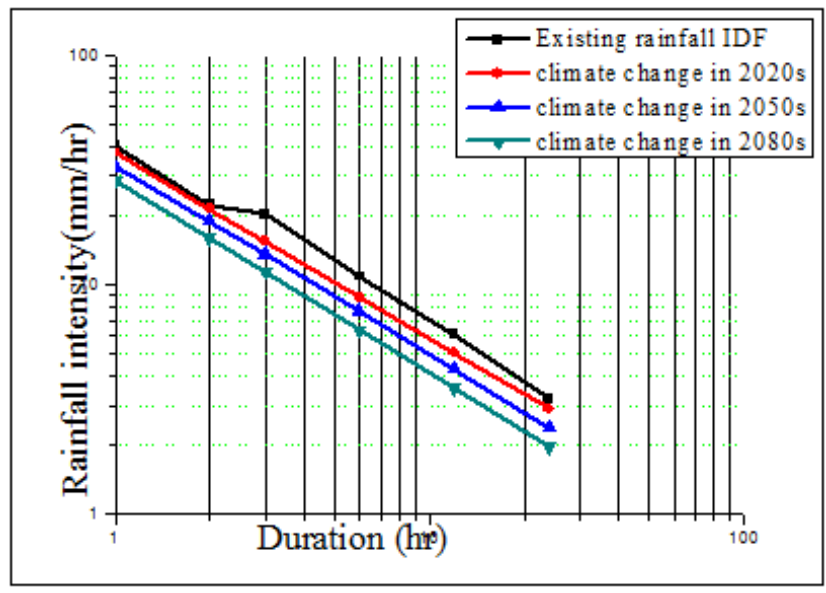

c) For 10 year return period

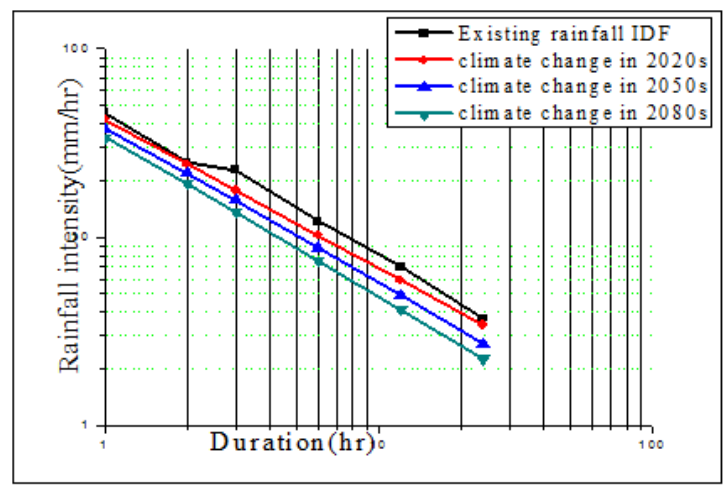

d) For 25 year return period

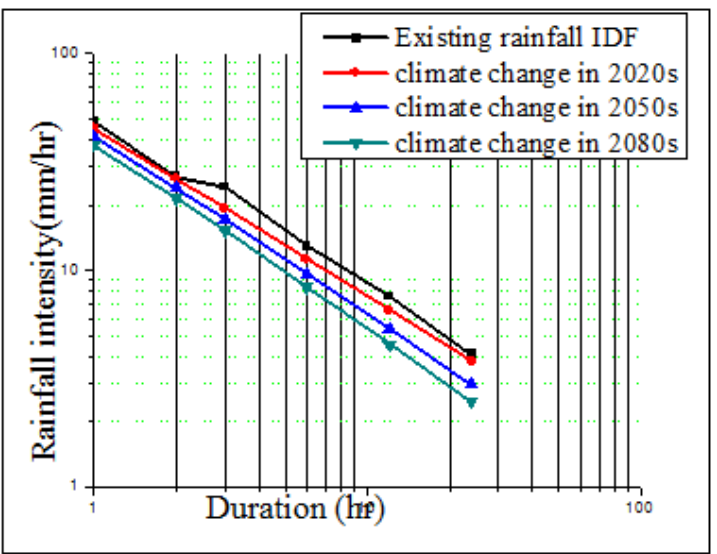

e) For 50 year return period

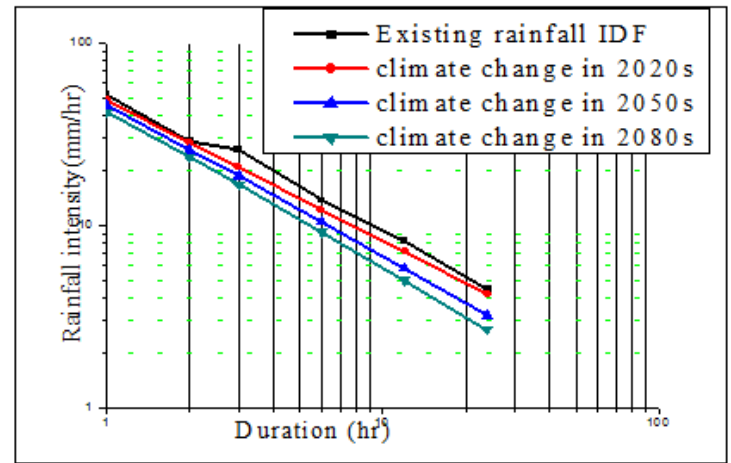

f) for 100 year return period

Figure 5. Comparison of rainfall IDF for the given return periods for Hurso station.

The comparisons of IDF curves developed, at Hurso station for climate change scenario with the IDF curves developed by historic rainfall tell that the current estimate values are up to $1.74 \%$ higher than that of historic rainfall in 2020 s, while in 2050s and 2080s climate scenario produces values up to $34 \%$ and $67 \%$ less than that of historic rainfall respectively. The relative results indicate that difference between rainfall intensities (percentage) of climate change scenario and historic rainfall for 2080s ranges between $0.71 \%$ and $55.93 \% \mathrm{i}$ with average value of approximately $28.32 \%$ in Chiro station. Similarly, in the case of Hurso station the difference between climate change scenario and 
historic rainfall for 2080 s varied from $19.44 \%$ to $67.75 \%$ with average value of approximately $43.6 \%$.

Generality from the results the rainfall magnitude will be different, Rainfall Intensity will increase for both GCMs in the future and the climate scenario reveals, significant increase/decrease in rainfall intensity for a range of durations and return periods, and the decrease in rainfall intensity and magnitude may have major implications on ways in which current (and future) water management infrastructure is designed, operated, and maintained.

\section{Conclusion and Recommendation}

Study of the rainfall intensity, duration and frequency (IDF) curves under changing climate relationship is one of the most important tools used to estimate the intensity and duration of an extreme rainfall event which is ultimately required for planning and design of drainage works, water resource systems and flood control, culvert design and for soil conservation interventions. Having the daily observed rainfall data, SDSM is designed to downscale climate information from coarse-resolution of GCMs to local or site level and were applied here to downscale the rainfall for the study area. Using this modified historic daily rainfall data, the rainfall intensity-duration-frequency relationships (IDFrelationships) were developed and compared with the existing one. The IDF-relationships give an idea about the frequency or return period of rainfall intensity or rainfall volume that can be expected within a certain period, i.e. the storm duration. The IDF curves are therefore critical in the design of hydraulic structures (such as bridges and culverts) to ensure that they are built economically and safely. Hence, accurate and reliable rainfall IDF establishments are needed to ensure that appropriately safe and economical designs are achieved.

The newly developed IDF curves from values of different scenarios are unable to present an accurate estimate of future extreme rainfall, butthey establish a significant fact: that the future climate will not be the same as the historic one and rainfall patterns in the study area will certainly change in future due to climate change. The current IDF curves should be revised to reflect the potential impact of climate change on hydrological structures and on new infrastructure and For the use of any models input data should be checked for missing and unrealistic values in order get accurate results

\section{References}

[1] Cubash, U.; Meehl, G. A.; Boer, G. J.; Stouffer, R. J.; Dix, M.; Noda, A.; Senior, C. A.; Raper, S.; and Yap, K. S. 2001. Projections of Future Climate Change. In: Climate Change 2001: The Scientific Basis. Contribution of Working Group I to the Third Assessment Report of the Intergovernmental Panel on Climate Change [Houghton, J. T., Y. Ding, D. J. Griggs, M. Noguer, P. J. van der Linden, X. Dai, K. Maskell, and C. A. Johnson (eds.)]. Cambridge University Press, Cambridge, United Kingdom and New York, NY, USA, 881pp.
[2] IPCC (International Panel on Climate Change), 2007: Climate Change 2007: The Physical Science Basis. Contribution of Working Group I to the Fourth Assessment Report of the Intergovernmental Panel on Climate Change [Solomon, S., D. Qin, M. Manning, Z. Chen, M. Marquis, K. B. Averyt, M. Tignor and H. L. Miller (eds.)]. Cambridge University Press, Cambridge, United Kingdom and New York, NY, USA, 996 pp.

[3] Mc Cuen, R. H., P. A. Johnson and R. M. Ragan, 1996. Highway Hydrology. Hydraulic Design Series NO. 2. Federal Highway Administration Office of Technology Applications. Washington, D. C.

[4] Suresh, R., 2005. Watershed hydrology: Principles of Hydrology. Standard Publishers Distributors. Delhi.

[5] EXACT (Executive Action Team). 2006. Middle East Water Data Banks Project. Application of Methods for Analysis of Rainfall Intensity in Areas of Israeli, Jordanian, and Palestinian Interest. Water resources of Palestinian, Jordanian, and Israeli Interest.

[6] Raiford, J. P., N. M. Aziz, A. A. Khan, and D. N. Powell, 2007. Rainfall Depth-Duration Frequency Relationships for South Carolina, North Carolina, and Georgia. American Journal of Environmental Sciences.

[7] NMSA (National Meteorological Service Agency), 1996.Assessment of Drought in Ethiopia. No. 2. Addis Ababa, Ethiopia.

[8] Nhat, M. L.; Tachikawa, Y.; and Takara, K. 2006. Derivation of Rainfall Intensity-Duration-Frequency Relationships for Short.

[9] Duration Rainfall from Daily Data. Disaster Prevention Research Institute, Kyoto University, Uji, Kyoto 611-0011, Japan.

[10] Tesfaye Morka, 2011. Development of Rainfall IntensityDuration -Frequency Curves for some selected stations under changing climate, Eastern Hararghe zone, Oromia. MSc. Thesis. Haramaya University. Haramaya, Ethiopia.

[11] Prodanovic, P. and S. P. Simonovic, 2009. Revision of Intensity-Duration-Frequency under Changing Climatic Conditions. $5^{\text {th }}$ International Symposium on Flood Defense: Managing Flood Risk, Reliability and Vulnerability, Toronto, Ontario, Canada.

[12] Garg, S. K. 1999. Irrigation Engineering and Hydraulics Structures. Khanna Publisher. New Delhi.

[13] Chowdhury, J. U.; Stedinger, J. R.; and LU, L. H. 1991. Goodness-of-fit Test for Regional GEV Flood Distribution. Water Resource Research 27, 1765 - 1776.

[14] Vogel, R. M. and D. E. Mc Martin, 1991. Probability plot Goodness-of-fit and Skewness Estimation Procedures for the Pearson Type 3 Distribution. Water Resource Research 27, 3149- 3158 .

[15] Ahmad, M. I., C. D. Sinclair and B. D. Spurr, 1988. Assessment of Flood Frequency Models Using Empirical Distribution Function. Journal of Water Resource 24, 1323-1328.

[16] Hosking, J. R. M. 1986. The Theory of Probability Weighted Moments. Research Report RC12210. IBM Research Division. New York. Bhakar, S. R., A. K. Bansal, N. Chhajed and R. C. Purohit, 2006. Frequency Analysis of Consecutive Days Maximum Rainfall at Banswara, Rajasthan, India. Department of Soil and Water Engineering, Udaipur, Rajasthan, India. Vol. 1, No. 3. 
[17] Feleke Gerbi, 2006. Development of Intensity-DurationFrequency Relationships for the SNNPR. MSc. Thesis. Arbaminch University, Arbaminch, Ethiopia.

[18] Shimelis Berhanu, 2008. Rainfall Intensity-DurationFrequency Analysis for Parts of Eastern Oromia. MSc. Thesis. Haramaya University. Haramaya, Ethiopia.

[19] Chali Edosa, 2008. Regional Rainfall Intensity-DurationFrequency Analysis for Oromia Region. MSc. Thesis. Arba Minch University. Arb Minch, Ethiopia.
[20] Prodanovic, P. and S. P. Simonovic, 2008.Intensity-DurationFrequency under Changing Climatic Conditions. $4^{\text {th }}$ International Symposium on Flood Defense: Managing Flood Risk, Reliability and Vulnerability, Toronto, Ontario, Canada.

[21] Cherkos Tefera, 2002. Intensity-Duration-Frequency Relationships for Northern half of Ethiopia. MSc. Thesis. Addis Ababa University. 